\title{
Lower Protrusion of a Copper-Nickel Alloy in a Through-Silicon via and Its Numerical Simulation
}

\author{
Hoon Sun Jung ${ }^{1}$, Young-Joo Jang ${ }^{2}$, Sung-Hoon Choa ${ }^{1, *}$ and Jae Pil Jung ${ }^{2, *}$ \\ ${ }^{1}$ Graduate School of NID Fusion Technology, Seoul National University of Science and Technology, \\ Seoul 139-743, Republic of Korea \\ ${ }^{2}$ Department of Materials Science and Engineering, University of Seoul, Seoul 130-743, Korea
}

\begin{abstract}
The application of Cu-filled through-silicon via (TSV) in 3-D integrated circuit packaging faces several fabrication and reliability issues. In this study, we introduced a $\mathrm{Cu}-\mathrm{Ni}$ alloy for TSV filling with a high filling speed and a reduced TSV protrusion. In particular, the characteristics of $\mathrm{Cu}-\mathrm{Ni}$ via protrusions at various annealing temperatures $\left(\sim 200-450^{\circ} \mathrm{C}\right)$ were investigated with experimental and numerical analysis and compared with $\mathrm{Cu}$-filled vias. High speed $\mathrm{Cu}-\mathrm{Ni}$ alloy filling into the vias was achieved without any defects by an electroplating process that used a periodic pulse reverse current waveform. The Cu-Ni alloy TSV showed lower via protrusion than the $\mathrm{Cu}$ TSV. The simulated protrusion heights of the $\mathrm{Cu}-\mathrm{Ni}$ vias were in good agreement with the experimental results. The simulation results also indicated that the $\mathrm{Cu}-\mathrm{Ni}$ TSVs has smaller protrusions than the Cu TSVs. As the annealing temperature was varied from 200 to $450^{\circ} \mathrm{C}$, the protrusions increased gradually and became significant at an annealing temperature of $350^{\circ} \mathrm{C}$. When the temperature was increased further, the protrusions became larger due to severe creep deformation. The von Mises stress also increased with increasing annealing temperature, and increased substantially at a temperature of $300^{\circ} \mathrm{C}$ due to the creep effect. In summary, the Cu-Ni alloy TSVs showed smaller protrusions relative to the $\mathrm{Cu}$ TSVs. The stress level of the $\mathrm{Cu}-\mathrm{Ni}$ via was lower than that of the $\mathrm{Cu}$ via. These results indicate that the $\mathrm{Cu}-\mathrm{Ni}$ alloy TSV had advantages in terms of high speed filling and smaller protrusions, demonstrating its promise as an alternative to current $\mathrm{Cu}$ TSV technologies. [doi:10.2320/matertrans.M2015335]
\end{abstract}

(Received August 24, 2015; Accepted September 14, 2015; Published November 25, 2015)

Keywords: via protrusion, through-silicon via (TSV), copper-nickel filling, thermo-mechanical stress, finite element analysis (FEA)

\section{Introduction}

Although through-silicon vias (TSVs) have great potential to be used in 3-D IC packaging, there are still many problems to overcome in order to achieve mass production with low cost. In general, TSV technologies utilize copper $(\mathrm{Cu})$-filling by the electroplating method ${ }^{1,2)}$ due to the good electrical properties and easy processing of $\mathrm{Cu}$. However, $\mathrm{Cu}$-filling still faces several reliability and manufacturability issues. Firstly, the coefficient of thermal expansion (CTE) of copper $\left(\sim 17.5 \times 10^{-6} /{ }^{\circ} \mathrm{C}\right)$ is much higher than that of silicon $\left(\sim 2.5 \times 10^{-6} /{ }^{\circ} \mathrm{C}\right)$ and the surrounding dielectric materials. As a result, copper expands five to six times more than silicon during high temperature fabrication or environmental temperature cycling. The thermo-mechanical stress caused by this CTE mismatch results in several reliability concerns such as interfacial delamination, cracking, voiding, and TSV protrusion. ${ }^{3,4)} \mathrm{Cu}$ protrusions in TSVs, also known as $\mathrm{Cu}$ pumping and $\mathrm{Cu}$ extrusion, have been discussed recently in the literature. ${ }^{5,6)}$ During the fabrication of TSVs, the vias undergo thermal annealing at up to $\sim 450^{\circ} \mathrm{C}$ with metallization and/or bonding processes at $\sim 250^{\circ} \mathrm{C}$. At any high temperature step of the TSV manufacturing process, the copper, which is confined in the via hole, will expand in the vertical direction and subsequently extrude out of the Si wafer surface (due to its higher $\mathrm{CTE}$ ). $\mathrm{Cu}$ protrusion can lead to cracking or delamination of the overlying dielectric and/or metal layers. Since $\mathrm{Cu}$ protrusion is a critical problem in the back-end-ofline (BEOL) process, several studies have been conducted to characterize and alleviate this phenomenon using experimental and numerical simulation methods. ${ }^{7,8)}$ It has been determined that $\mathrm{Cu}$ protrusion is not fully-reversible and that localized

*Corresponding author, E-mail: shchoa@seoultech.ac.kr,jpjung@uos.ac.kr plastic deformation plays an important role in TSV protrusion. ${ }^{9)}$ Optimization of the annealing conditions is known to be an important factor to avoid further plastic deformation of copper in the vias. ${ }^{9)}$ Secondly, Cu-filling of the vias normally takes a long time ( approximately $15 \mathrm{~h}$ ), and defects are most likely to occur at longer filling times. ${ }^{10)}$ These long processing times represent a huge drawback for the commercial realization of TSV technologies. To reduce the $\mathrm{Cu}$-filling time, a pulse-reverse (PR) current waveform (modified from the pulse current) ${ }^{11,12)}$ or the addition of inhibitors and accelerators to the plating solution have been reported. ${ }^{13)}$

As a fundamental solution to overcome these problems, several recent studies have looked into replacing copper with different filling materials, such as tungsten, ${ }^{14)}$ polymers, ${ }^{15)}$ alloys, ${ }^{16)}$ and solders, ${ }^{17)}$ in an attempt to reduce the thermomechanical stress and shorten the Cu-filling time. He et al. ${ }^{18)}$ suggested a $\mathrm{Cu}$-cored solder for rapid and low-cost processing for TSV fabrication. Ko et al. ${ }^{19)}$ introduced a vacuumassisted via filling method with a molten solder. They reported that the filling time for vias with a diameter of $30 \mu \mathrm{m}$ was only $0.5 \mathrm{~s}$, which was substantially faster compared to conventional electroplating methods. In the authors' previous study, ${ }^{20)}$ we demonstrated a high speed $\mathrm{Cu}-\mathrm{Ni}$ alloy filling method into TSVs where a periodic pulse reverse (PPR) current waveform was applied to reduce the filling time of the electroplating. Although several alternative filling materials are suggested, little attention has been paid to $\mathrm{Cu}$ protrusions and limited information about this subject is currently available. In this study, we investigated the characteristics of TSV protrusions for high speed $\mathrm{Cu}-\mathrm{Ni}$ alloy filling in comparison with $\mathrm{Cu}$-filling. TSV protrusions at various annealing temperatures were experimentally characterized. Finite element analysis (FEA) simulations were also used to investigate TSV protrusion behavior. 


\section{Experimental Procedure}

To fabricate the TSV structure, a $\langle 100\rangle$ p-type Si wafer (100 $\mathrm{mm}$ in diameter and $525 \mu \mathrm{m}$ in thickness) was used as a substrate. A photo resist (PR, AZ4620) was spin-coated to produce via holes on the wafer surface. Subsequently, the wafer was etched by the deep reactive ion etching (DRIE) method. An array of TSVs $(30-\mu \mathrm{m}$ diameter, 200- $\mu \mathrm{m}$ pitch, and $60-\mu \mathrm{m}$ depth) was fabricated. Each $5 \mathrm{~mm} \times 5 \mathrm{~mm}$ wafer was composed of 240 chips, and 256 vias were prepared in each chip. $\mathrm{A} \mathrm{SiO}_{2}$ layer with a thickness of $1 \mu \mathrm{m}$ was formed as an insulation layer by the plasma enhanced chemical vapor deposition (PECVD). Ti $(300 \mathrm{~nm})$ and $\mathrm{Au}(500 \mathrm{~nm})$ layers were sputtered in the via walls as adhesion and seed layers, respectively. The Si wafer was cut into chips with a diamond saw. The diced chips were used as the cathode for $\mathrm{Cu}$-filling by electroplating, and a Pt sheet (size: $10 \mathrm{~mm} \times 10 \mathrm{~mm} \times$ $0.3 \mathrm{~mm}$ ) was used as the anode. A commercial pulse-plating unit (EPP-4000 from Princeton Applied Research) was used as the power supply for electroplating. The reference electrode for electroplating was a standard calomel electrode (SCE). The electroplating solution for $\mathrm{Cu}-\mathrm{Ni}$ filling was composed of 150 200 g/l of $\mathrm{CuSO}_{4}, 150 \sim 200 \mathrm{~g} / 1$ of $\mathrm{NiSO}_{4}$, $32 \mathrm{ml} / 1$ of $\mathrm{H}_{2} \mathrm{SO}_{4}$, and additives. The electrolyte in the plating bath was stirred continuously by a magnetic bar at $200 \mathrm{rpm}$ (revolutions per minute), and the electrolyte was kept at room temperature during electroplating. The schematic diagram for the experimental setup is shown in Fig. 1. A periodic pulse reverse current was used to avoid high concentrations of ions in the opening region of the via. Therefore, the ion concentration is homogenized throughout the via, and clogging of the via opening is prevented during the application of the pulse (reduction) current. A more detailed fabrication procedure is explained in Ref. 20).

After filling the $\mathrm{Cu}-\mathrm{Ni}$ alloy into the via, any $\mathrm{Cu}-\mathrm{Ni}$ overflow on top of the wafer surface was removed by the chemical mechanical polishing (CMP) process. The $\mathrm{Cu}-\mathrm{Ni}$ filled TSV wafer was annealed at a high temperature, ranging

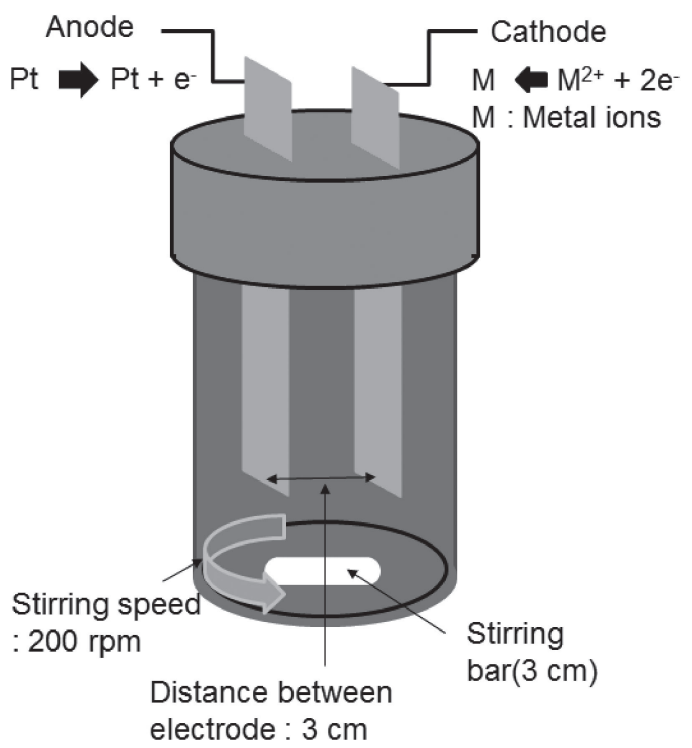

Fig. 1 Schematic illustration of the electroplating unit for $\mathrm{Cu}-\mathrm{Ni}$ filling into the via.

from $200^{\circ} \mathrm{C}$ to $450^{\circ} \mathrm{C}$, using a vacuum furnace. The heating rate was maintained at $5^{\circ} \mathrm{C} / \mathrm{min}$ for an annealing duration of $30 \mathrm{~min}$. $\mathrm{Cu}-\mathrm{Ni}$ alloy-filled vias were observed by field emission scanning electron microscopy (FE-SEM, HitachiS4300) to investigate the filling ratio of the vias and to observe the deposition morphology. $\mathrm{Cu}-\mathrm{Ni}$ TSV protrusions were measured with atomic force microscopy (AFM). An electron probe micro analyzer (EPMA, JEOL JXA-8500F) was used to investigate the elemental analysis of the filled $\mathrm{Cu}-\mathrm{Ni}$ alloy vias.

\section{Results and Discussions}

Figure 2 shows SEM images of the via protrusion shapes for the $\mathrm{Cu}-\mathrm{Ni} \mathrm{TSV}$ s with annealing temperature ranging from $200^{\circ} \mathrm{C}$ to $450^{\circ} \mathrm{C}$. The SEM images show that the protrusion height increases with the annealing temperature. In order to (a)

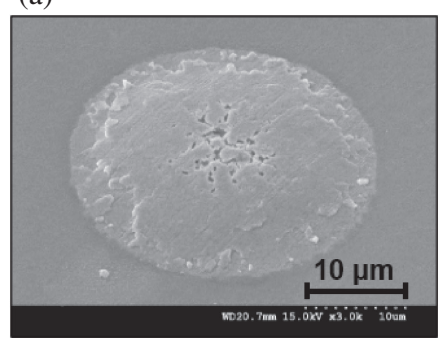

(d)

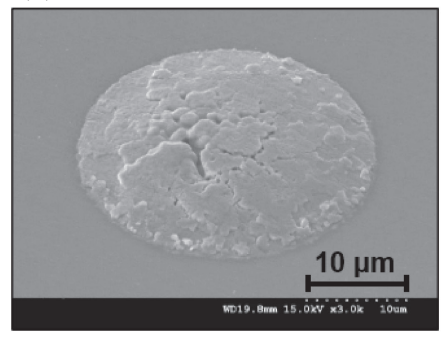

(b)

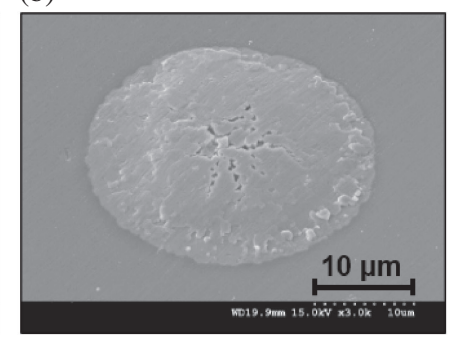

(e)

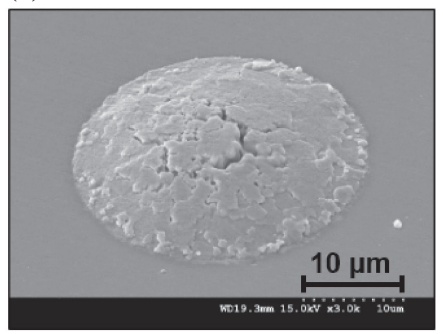

(c)

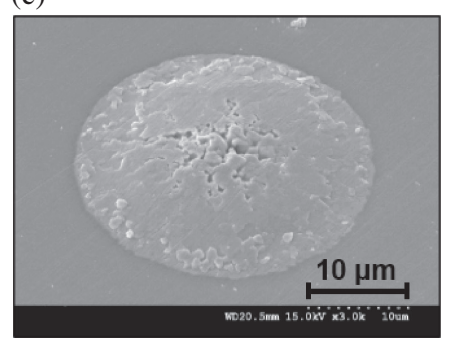

(f)

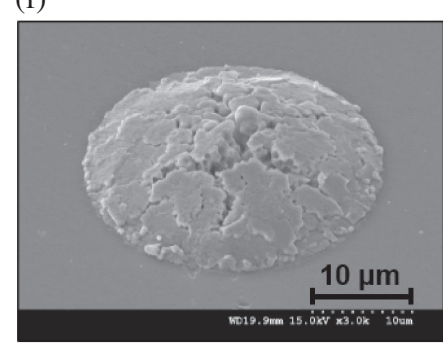

Fig. 2 SEM images of Cu-Ni filled via protrusions at various annealing conditions: (a) $200^{\circ} \mathrm{C}$, (b) $250^{\circ} \mathrm{C}$, (c) $300^{\circ} \mathrm{C}$, (d) $350^{\circ} \mathrm{C}$, (e) $400^{\circ} \mathrm{C}$, and (f) $450^{\circ} \mathrm{C}$. 
precisely measure the protrusion height of the extruded $\mathrm{Cu}$ Ni TSV, AFM was used. Figure 3 shows AFM images of the protruded vias for each annealing temperature. Via protrusions begin to be visually observable at the annealing temperature of $300^{\circ} \mathrm{C}$. Figure 4 shows a plot of the maximum protrusion height as a function of annealing temperature. It is clear that the protrusion height increases with annealing temperature. The protrusion height at $300^{\circ} \mathrm{C}$ is $260 \mathrm{~nm}$, which is a relatively small protrusion. Protrusions start to increase substantially at $350^{\circ} \mathrm{C}$. At an annealing temperature of $450^{\circ} \mathrm{C}$, the protrusion height increases to $1250 \mathrm{~nm}$. To compare the protrusion amount of $\mathrm{Cu}-\mathrm{Ni}$ filled TSVs with that of conventional $\mathrm{Cu}$-filled TSVs, we fabricated $\mathrm{Cu}$-filled TSVs separately and measured their protrusion height at $450^{\circ} \mathrm{C}$. The protrusion height of the $\mathrm{Cu} \mathrm{TSV}$ at an annealing temperature of $450^{\circ} \mathrm{C}$ was $1360 \mathrm{~nm}$ (solid rectangular symbol in Fig. 4), which showed a higher value than that of the $\mathrm{Cu}-$ $\mathrm{Ni}$ TSV. We did not measure the change in the $\mathrm{Cu}$ protrusion height at various annealing temperatures because there have already been several reports detailing the measurements of $\mathrm{Cu}$ TSV protrusions. ${ }^{5,6,9)}$ It is clear that the $\mathrm{Cu}-\mathrm{Ni}$ TSV shows lower via protrusion than the conventional $\mathrm{Cu}$ TSV. However, a protrusion height of $1.25 \mu \mathrm{m}$ is still high enough to cause fracture of the overlying BEOL layer. The values of the protrusion heights in this study are actually relatively larger than those reported in previous studies. ${ }^{5,6,9)}$ This is caused by the fact that the via diameter in our study is larger than those in previous studies; previous researchers used smaller vias with diameters less than $10 \mu \mathrm{m}$. It is well known that $\mathrm{Cu}$ protrusion from TSVs increases with increasing via diameters. Larger vias will result in larger protrusions due to the larger $\mathrm{Cu}$ volume. ${ }^{7)}$ Therefore, we expect that the protrusion height will decrease if we reduce the via diameter.

The $\mathrm{Cu}-\mathrm{Ni}$ alloy samples were observed by FE-SEM to investigate the filling ratio of the vias and to observe the deposition morphology. Furthermore, the EPMA was used to investigate the elemental analysis of the filled $\mathrm{Cu}-\mathrm{Ni}$ alloy TSVs. Figure 5 presents SEM images and EPMA mappings for cross-sections of the $\mathrm{Cu}-\mathrm{Ni}$ filled vias. SEM analysis showed that a complete filling ratio was achieved without serious defects or voids. Even after aging this sample at $450^{\circ} \mathrm{C}$ for $30 \mathrm{~min}$, an interfacial delamination or a crack at the interface between the $\mathrm{Cu}-\mathrm{Ni}$ alloy in $\mathrm{TSV}$ and $\mathrm{SiO}_{2}$ insulation layer was not observed. Using FE-SEM images, the $\mathrm{Cu}-$ filling ratio was measured by the commercial program, Carl Zeiss Zxiovision. In the EPMA analysis, $\mathrm{Cu}$ and $\mathrm{Ni}$ exhibited a nearly identical distribution across the via hole. EPMA results indicated that the composition of the $\mathrm{Cu}-\mathrm{Ni}$ alloy via consisted of 92 mass $\% \mathrm{Cu}$ and 8 mass $\% \mathrm{Ni}$. The uniform distribution of $\mathrm{Cu}$ and $\mathrm{Ni}$ in the $\mathrm{Cu}-\mathrm{Ni}$ alloy via did not change with increasing annealing temperature.

In this paper, finite element analysis was used to investigate $\mathrm{Cu}-\mathrm{Ni}$ TSV protrusions. Figure 6 shows a geometrical schematic diagram of the TSV structure. The isolated blind TSV was modeled, and quarter symmetric FEA models were adopted for computational efficiency. The silicon substrate is $70 \mu \mathrm{m}$ in thickness and $80 \mu \mathrm{m}$ square. The diameter and depth of the TSV are $30 \mu \mathrm{m}$ and $60 \mu \mathrm{m}$, respectively. The thickness of the silicon oxide barrier layer is $1 \mu \mathrm{m}$. Figure 7 shows the quarter symmetric FEM modeling of the $\mathrm{Cu}-\mathrm{Ni} \mathrm{TSV}$ structure. The symmetric boundary condition was applied onto two vertical cutting sides of the structure, and one node at the origin of global coordinate system was additionally constrained for the $x, y$, and $z$ axes.

FEAs of $\mathrm{Cu}-\mathrm{Ni}$ TSV protrusions were conducted at various annealing temperatures. In simulation, the elastic-plastic behaviors of $\mathrm{Cu}$ and $\mathrm{Cu}-\mathrm{Ni}$ alloy are not sufficient to predict the protrusion behavior at high temperatures due to creep effects. It is well known that copper will creep at a high fraction $(>0.4)$ of its melting temperature $\left(1083^{\circ} \mathrm{C}\right)$. Therefore, it is thought that $\mathrm{Cu}$ or $\mathrm{Cu}-\mathrm{Ni}$ alloy could creep under annealing temperatures above $300^{\circ} \mathrm{C}$. Therefore, in this study, elastic-creep properties were used to consider the creep behavior of $\mathrm{Cu}$ and $\mathrm{Cu}-\mathrm{Ni}$ alloy. The other materials were regarded elastic materials. Table 1 shows the material properties used in the FEM simulation., ${ }^{7,22}$ Since the material properties of 92 mass $\% \mathrm{Cu}$ and 8 mass\% $\mathrm{Ni}$ alloy material did not exist in any literatures, we used an effective modulus concept in approximate calculation of elastic Young's modulus and CTE. The rule of mixture was applied to calculate the effective material properties. ${ }^{23)}$ The rule of mixture is constructed by two parameters namely the modulus and the volume fraction of each component of the material. For $\mathrm{Cu}$ and $\mathrm{Cu}-\mathrm{Ni}$ alloy, the time dependent creep properties was used. The time hardening implicit creep equations with ANSYS FEA software were used in this study. For the simulation of $\mathrm{Cu}$ and $\mathrm{Cu}-\mathrm{Ni}$ alloy creep, we used the common creep relation of eq. (1) with a creep strain rate $\left(\dot{\varepsilon}_{\mathrm{cr}}\right)$, applied stress $(\sigma)$, temperature $(T)$, and time $(t)$ :

$$
\dot{\varepsilon}_{\mathrm{cr}}=A \exp \left(-\frac{Q}{R T}\right) \sigma^{n} t^{m}
$$

where $n$ and $m$ are the stress- and time-hardening exponents, respectively. $Q$ is the activation energy in $\mathrm{kJ} \mathrm{mol}^{-1}, R$ $\left(8.314 \mathrm{~J} \mathrm{~mol}^{-1} \mathrm{~K}^{-1}\right)$ is the universal gas constant, and $A$ is a constant. Creep constants of $\mathrm{Cu}$ were referenced from the existing literature. ${ }^{7)}$ For copper, the material constant $A$ is $1.43 \times 10^{10}, Q$ is $197 \mathrm{~kJ} \mathrm{~mol}^{-1}, n$ is 2.5 , and $m$ is -0.9 . For $\mathrm{Cu}-\mathrm{Ni}$ alloy material, the creep constant of 92 mass $\% \mathrm{Cu}$ and 8 mass \% Ni alloy material did not exist in any literatures. Only available $\mathrm{Cu}-\mathrm{Ni}$ alloy material in existing literatures, which has similar composition of 92 mass $\% \mathrm{Cu}$ and 8 mass $\%$ $\mathrm{Ni}$ alloy, was 97.6 mass\% $\mathrm{Cu}-2.2$ mass $\% \mathrm{Ni}-0.2$ mass\% $\mathrm{Be}$ alloy material. ${ }^{24}$ Therefore, we used the creep constants of 97.6\% $\mathrm{Cu}-2.2 \% \mathrm{Ni}-0.2 \%$ Be alloy material for creep simulation of the $\mathrm{Cu}-\mathrm{Ni}$ alloy TSV. For $\mathrm{Cu}-\mathrm{Ni}$ alloy, the creep constant $A$ is $1.07 \times 10^{9}, Q$ is $197 \mathrm{~kJ} \mathrm{~mol}^{-1}, n$ is 2.5 , and $m$ is -0.75 . The room temperature $\left(25^{\circ} \mathrm{C}\right)$ condition is assumed to be a stress-free condition where all materials in the TSV structure remain without any deformation. In order to simulate the actual annealing process, the numerical simulation was conducted in three steps. Firstly, the temperature was increased from room temperature $\left(25^{\circ} \mathrm{C}\right)$ to the annealing temperature $\left(200 \sim 450^{\circ} \mathrm{C}\right)$ (ramp up step). Secondly, the temperature was hold at the annealing temperature (200 $450^{\circ} \mathrm{C}$ ) for $30 \mathrm{~min}$ at creep strain effect conditions (dwelling step). As a final annealing step, the TSV structure was cooled down to room temperature $\left(25^{\circ} \mathrm{C}\right)$. TSV protrusion simulation results were obtained at the final annealing step at which TSV was cooled down to room temperature. 


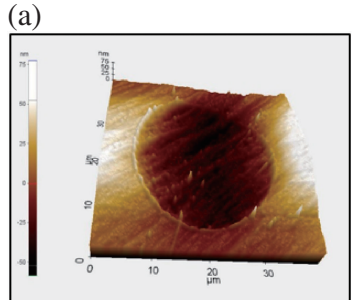

(b)

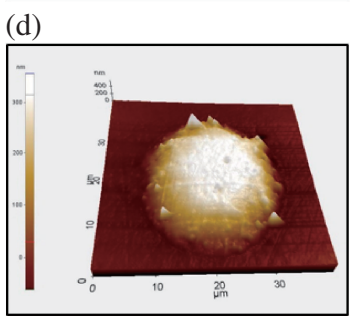

(e)

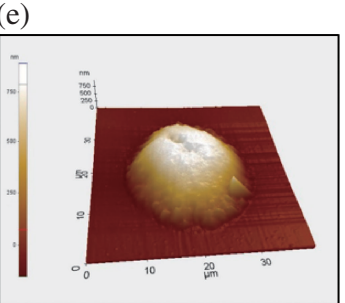

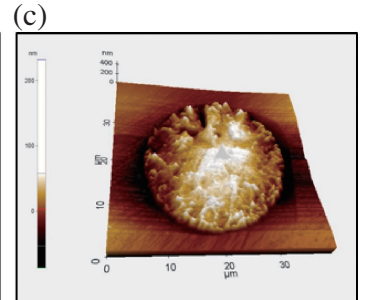

(f)

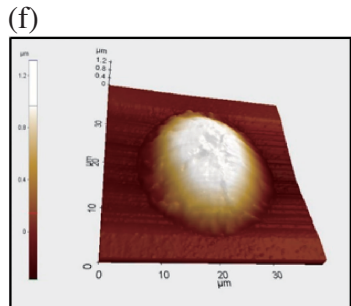

Fig. 3 AFM images of $\mathrm{Cu}-\mathrm{Ni}$ filled via protrusions at various annealing conditions: (a) $200^{\circ} \mathrm{C}$, (b) $250^{\circ} \mathrm{C}$, (c) $300^{\circ} \mathrm{C}$, (d) $350^{\circ} \mathrm{C}$, (e) $400^{\circ} \mathrm{C}$, and (f) $450^{\circ} \mathrm{C}$.

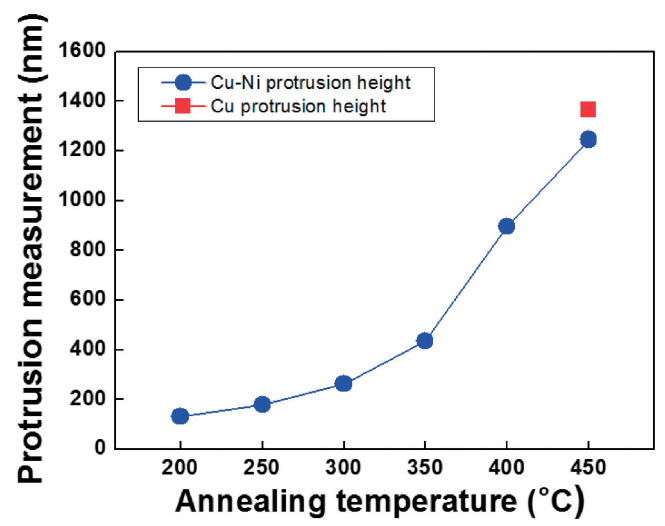

Fig. 4 AFM measurement results of $\mathrm{Cu}-\mathrm{Ni}$ via protrusions with increasing annealing temperature compared with $\mathrm{Cu}$ via protrusions.

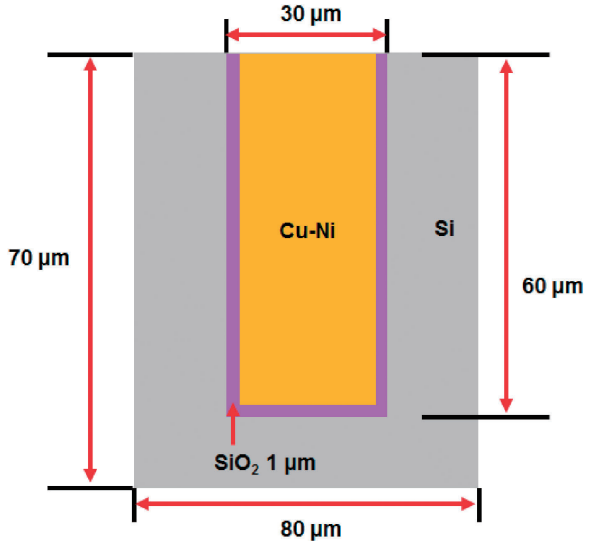

Fig. 6 Schematic drawing of the TSV structure used in the FEA study.
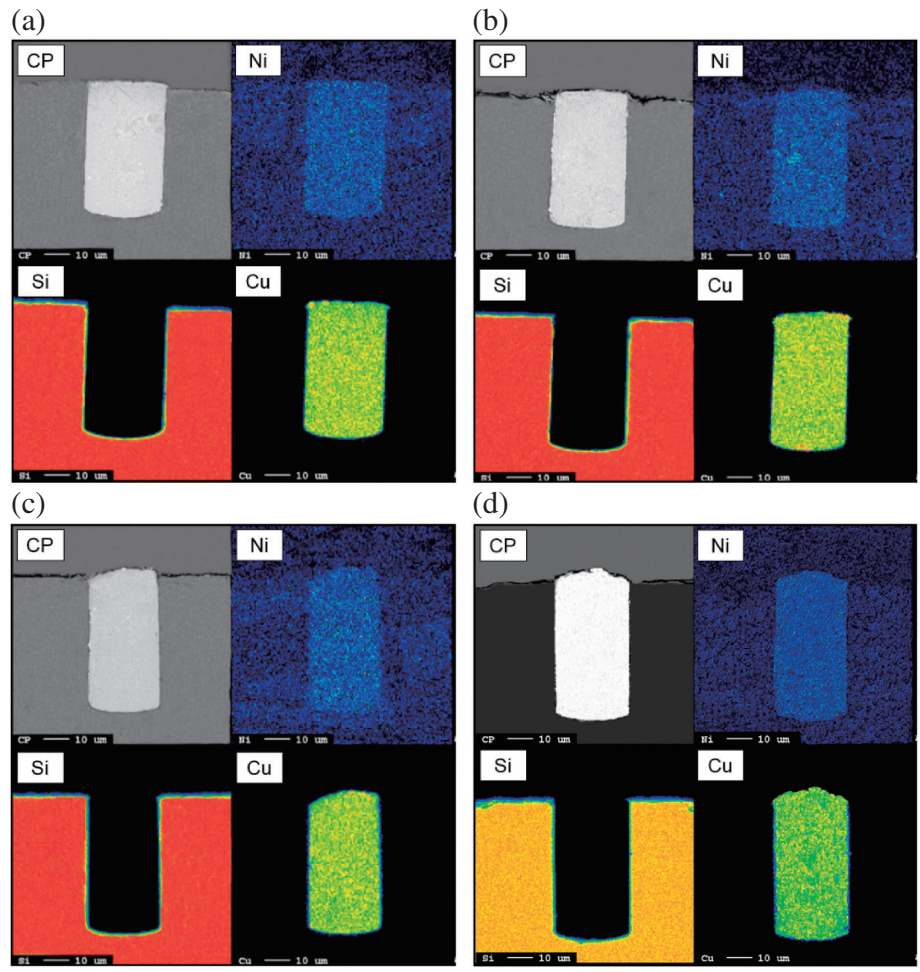

Fig. 5 EPMA mapping results of $\mathrm{Cu}-\mathrm{Ni}$ filling by PPR current waveform with various annealing temperatures: (a) $200^{\circ} \mathrm{C}$, (b) $300^{\circ} \mathrm{C}$,

(c) $400^{\circ} \mathrm{C}$, and (d) $450^{\circ} \mathrm{C}$. 


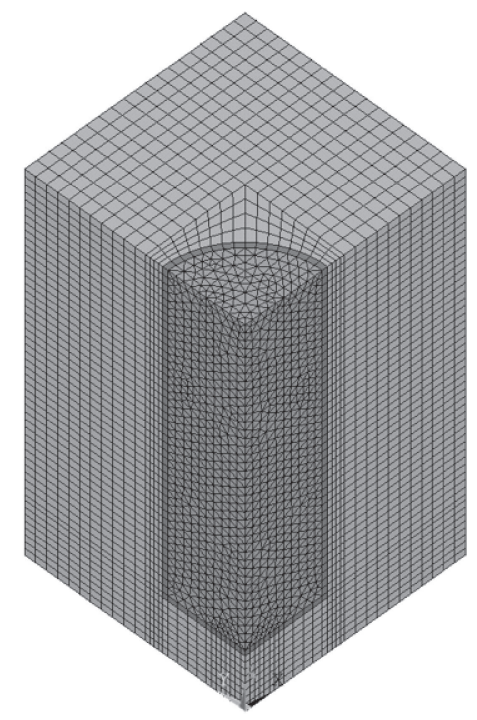

Fig. 7 Quarter symmetric FEM modeling developed for analysis of the $\mathrm{Cu}-$ Ni TSV structure.

Table 1 Material properties used in this study.

\begin{tabular}{cccc}
\hline Material & $\begin{array}{c}\text { Young's modulus } \\
(\mathrm{GPa})\end{array}$ & $\begin{array}{c}\text { Poison's ratio } \\
(v)\end{array}$ & $\begin{array}{c}\mathrm{CTE} \\
\left(\mathrm{ppm} /{ }^{\circ} \mathrm{C}\right)\end{array}$ \\
\hline $\mathrm{Si}$ & 131 & 0.28 & 2.8 \\
$\mathrm{SiO}_{2}$ & 73 & 0.17 & 0.5 \\
$\mathrm{Cu}$ & 91.7 & 0.34 & 17.6 \\
$\mathrm{Cu}-\mathrm{Ni}$ alloy & 95 & 0.34 & 17.4 \\
\hline
\end{tabular}

FEM analyses were conducted with various annealing temperatures ranging from $200^{\circ} \mathrm{C}$ to $450^{\circ} \mathrm{C}$ and compared with the experimental results. Figure 8 shows cross-sectional views of the simulated $\mathrm{Cu}$ and $\mathrm{Cu}-\mathrm{Ni}$ TSV deformations for various annealing temperatures; the displacements in the z-direction have been exaggerated by a factor of two times for better visualization. It can be clearly seen that $\mathrm{Cu}-\mathrm{Ni}$ protrudes out of the vias in the vertical direction when the temperature is increased to different annealing temperatures. The $\mathrm{Cu}-\mathrm{Ni}$ TSV showed less protrusion than $\mathrm{Cu}$ TSV. Figure 9 shows the simulated $\mathrm{Cu}-\mathrm{Ni}$ TSV protrusion heights in comparison with the experimentally measured data. The $\mathrm{Cu}-\mathrm{Ni}$ via protrusion increases with increasing annealing

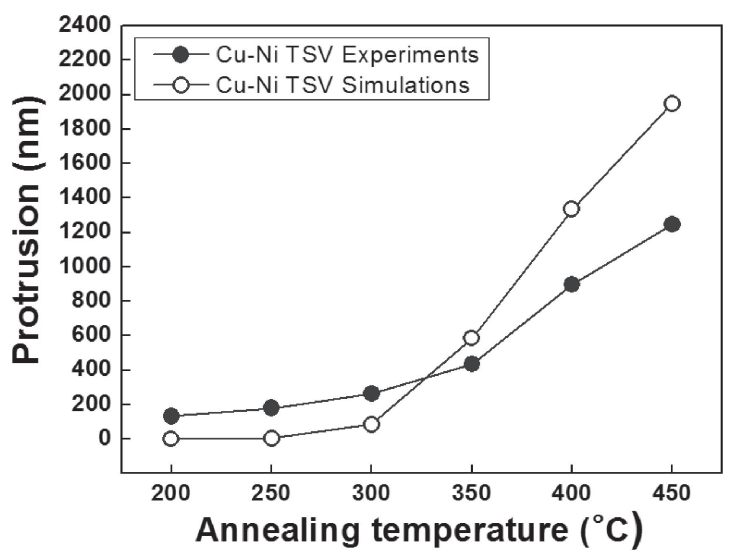

Fig. 9 The simulation and experimental results of $\mathrm{Cu}-\mathrm{Ni}$ TSV protrusion heights.

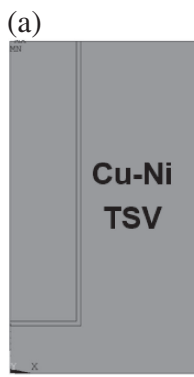

$200^{\circ} \mathrm{C}$

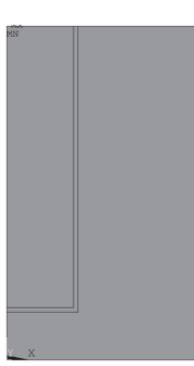

$250^{\circ} \mathrm{C}$

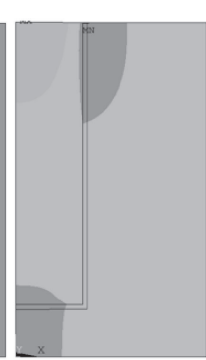

$300^{\circ} \mathrm{C}$

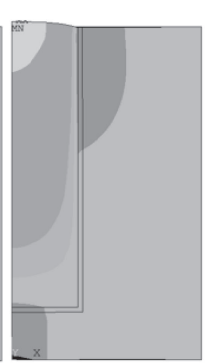

$350^{\circ} \mathrm{C}$

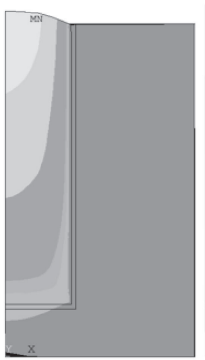

$400^{\circ} \mathrm{C}$

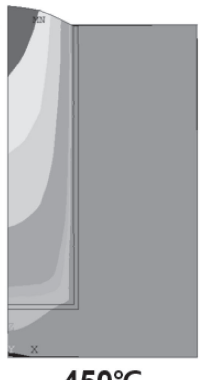

$450^{\circ} \mathrm{C}$

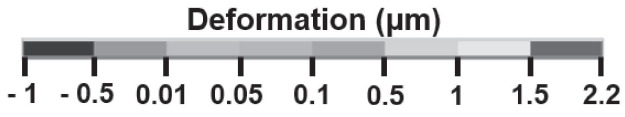

(b)

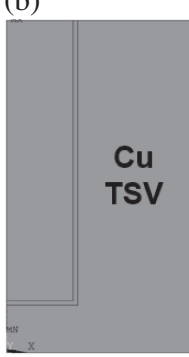

$200^{\circ} \mathrm{C}$

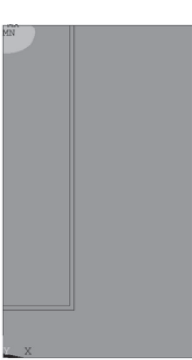

$250^{\circ} \mathrm{C}$

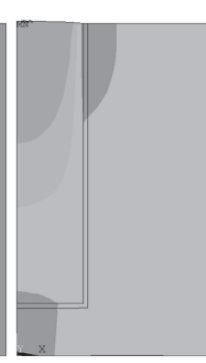

$300^{\circ} \mathrm{C}$

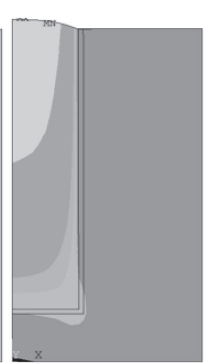

$350^{\circ} \mathrm{C}$

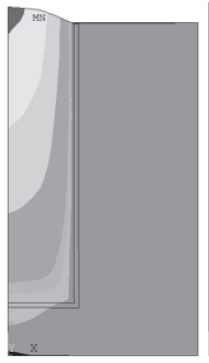

$400^{\circ} \mathrm{C}$

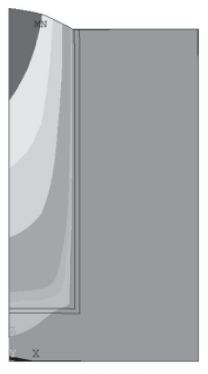

$450^{\circ} \mathrm{C}$

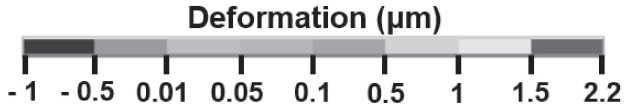

Fig. 8 The cross-sectional views of the TSV deformations for various annealing temperatures; the displacements in the z-direction are exaggerated two times for better visualization: (a) $\mathrm{Cu}-\mathrm{Ni}$ alloy TSV structure (b) $\mathrm{Cu}$ TSV structure. 


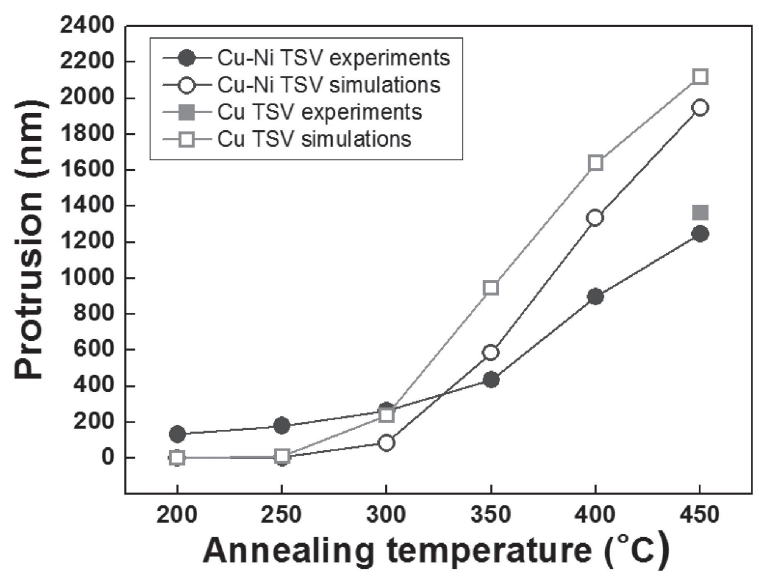

Fig. 10 The summary of the experimental and simulation results of the $\mathrm{Cu}$ $\mathrm{Ni}$ and $\mathrm{Cu}$ via protrusion heights. (a)

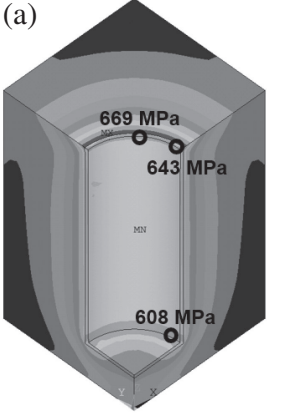

(b)

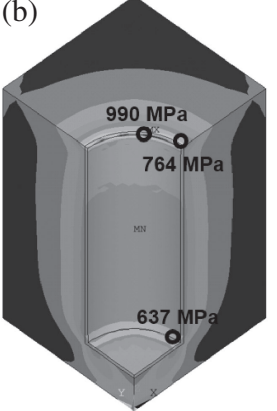

(c)

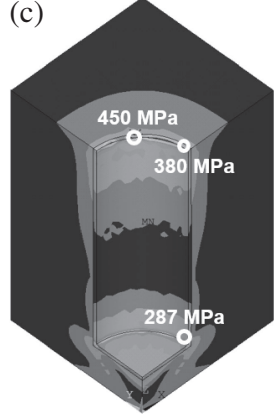

Fig. 12 The stress contour and stress values at the $\mathrm{SiO}_{2}$ layer and the interface between the via and the surrounding the oxide layer. (a) Ram up to an annealing temperature of $300^{\circ} \mathrm{C}$, (b) dwelling for $30 \mathrm{~min}$ at $300^{\circ} \mathrm{C}$, (c) ramp down from $300^{\circ} \mathrm{C}$ to room temperature.

(a)

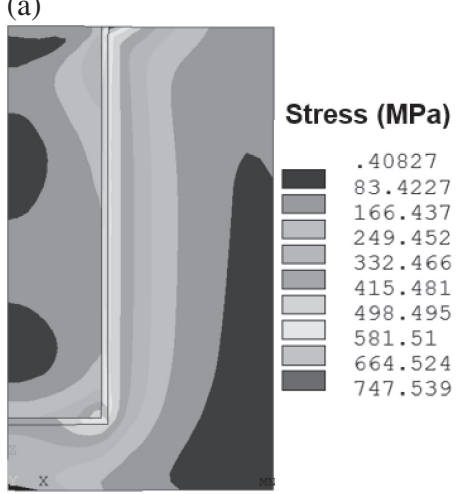

(b)

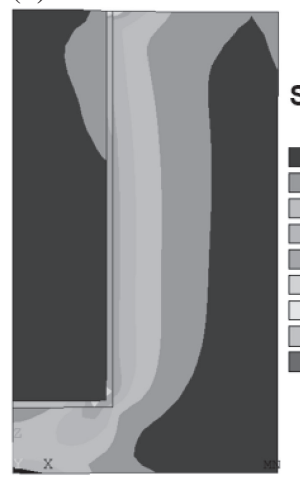

(c)

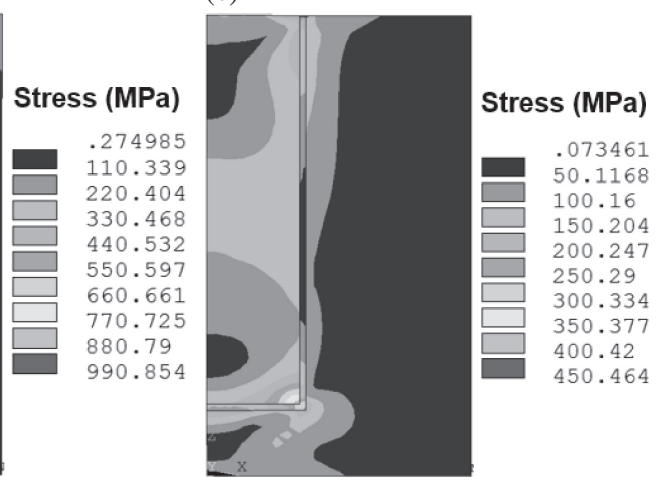

Fig. 11 The typical von Mises stress distribution of the cross-section of the $\mathrm{Cu}-\mathrm{Ni}$ TSV structure with increasing temperature. (a) Ram up to an annealing temperature of $300^{\circ} \mathrm{C}$, (b) dwelling for $30 \mathrm{~min}$ at $300^{\circ} \mathrm{C}$, (c) ramp down from $300^{\circ} \mathrm{C}$ to room temperature.

temperature. The results of the simulated $\mathrm{Cu}-\mathrm{Ni}$ via protrusion heights are relatively in good agreement with the experimentally measured data. The difference between the experimental results and simulation results could be attributed to the material properties used in the simulation such as creep constants as well as the experimental measurement errors. To compare the protrusions of the $\mathrm{Cu}-\mathrm{Ni} \mathrm{TSV}$ with the $\mathrm{Cu} \mathrm{TSV}$, the $\mathrm{Cu}$ TSV protrusion was also simulated using FEM. Figure 10 shows the summary of the experimental and simulation results of $\mathrm{Cu}-\mathrm{Ni}$ and $\mathrm{Cu}$ via protrusion height. The simulated maximum protrusion heights at $450^{\circ} \mathrm{C}$ for the $\mathrm{Cu}-\mathrm{Ni}$ and $\mathrm{Cu} \mathrm{TSV}$ were 1.94 and $2.11 \mu \mathrm{m}$, respectively. As shown in Fig. 10, both the experimental and simulation results indicate that the amount of protrusion of the $\mathrm{Cu}-\mathrm{Ni}$ TSV is smaller than the Cu TSV. The protrusion evolution behavior of the $\mathrm{Cu}-\mathrm{Ni} \mathrm{TSV}$, with increasing annealing temperature, is nearly identical with that of the $\mathrm{Cu}$ TSV. As the annealing temperature increases, $\mathrm{Cu}$ is expanded vertically because it is constrained by the surrounding $\mathrm{Si}$ substrate. Due to the thermal expansion (CTE) mismatch between $\mathrm{Cu}\left(\sim 16.7 \mathrm{ppm} /{ }^{\circ} \mathrm{C}\right)$ and the $\mathrm{Si}$ substrate $(\sim 2.3$ $\left.\mathrm{ppm} /{ }^{\circ} \mathrm{C}\right)$, thermal stresses build up inside the TSV when it is subjected to thermal treatment. ${ }^{3,7)}$ During the annealing process, irreversible deformation or plastic deformation occurs when the thermal stress in the $\mathrm{Cu}$ TSV is greater than the elastic limit of $\mathrm{Cu}$. When the annealing temperature is above $350^{\circ} \mathrm{C}$, protrusions become larger because of the large $\mathrm{Cu}$ creep deformation. Due to the irreversible creep deformation of copper, protruding $\mathrm{Cu}$ can never return to its original position when the TSV is cooled down to room temperature. Smaller protrusion of $\mathrm{Cu}-\mathrm{Ni} \mathrm{TSV}$ than $\mathrm{Cu}$ TSV might be attributed to a higher melting temperature of nickel composition, which is $1455^{\circ} \mathrm{C}$.

Figure 11 shows the typical von Mises stress distribution of the cross-section of the $\mathrm{Cu}-\mathrm{Ni}$ alloy TSV structure for the three annealing process steps which are ramping up to $300^{\circ} \mathrm{C}$, dwell for $30 \mathrm{~min}$, and cooling down to room temperature, respectively. The maximum stress occurs at the interface between the via and the surrounding oxide layer or Si. Particularly, the stress is mainly concentrated at the oxide layer of the top and bottom regions of the via. Figure 12 also shows the von Mises stress contour of $\mathrm{Cu}-\mathrm{Ni}$ alloy TSV for each annealing step. The stress level becomes the highest during the dwelling process. When the TSV structure was cooled down to room temperature, the stress was relaxed and the stress level became lower. The maximum stress value during the dwelling step is around $990 \mathrm{MPa}$ at the interface of the top regions of the oxide layer, and the maximum stress becomes $450 \mathrm{MPa}$ after cooling down to room temperature. The main reason for the stress buildup on the dielectric layer is caused by the larger volume of copper and its high CTE with respect to $\mathrm{SiO}_{2}$. 


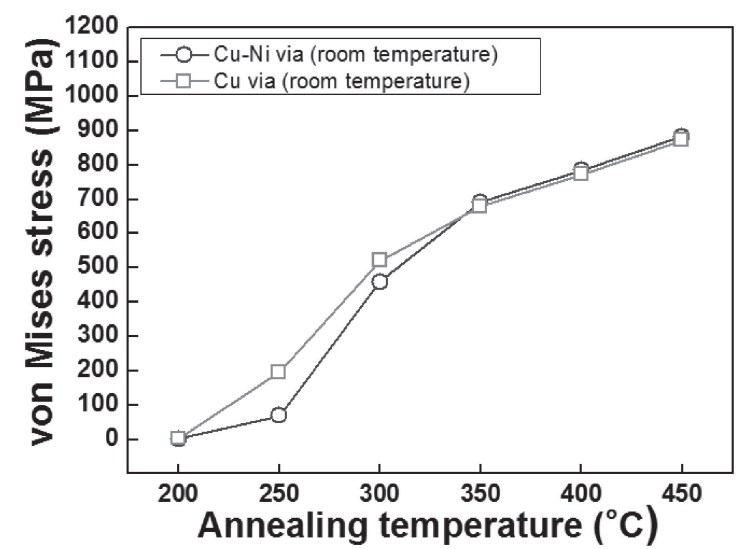

Fig. 13 Maximum von Mises stress of the TSV vias with increasing annealing temperature.

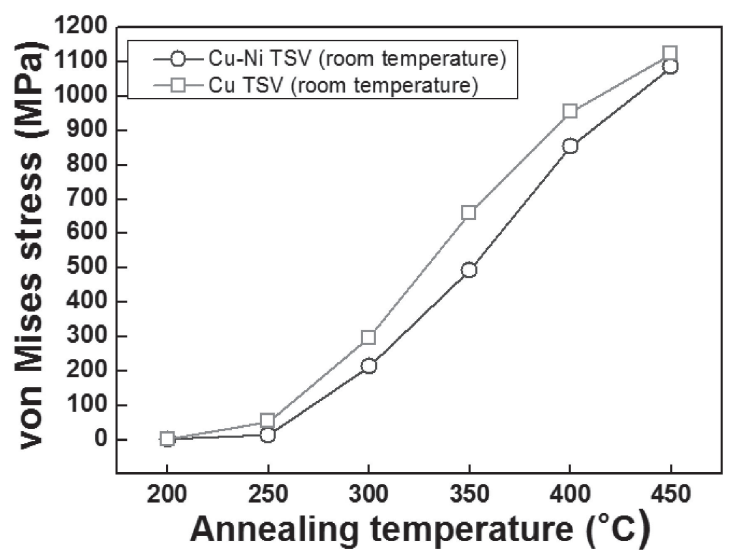

Fig. 14 Maximum von Mises stress of the silicon wafer with increasing annealing temperature.

Figure 13 shows the simulation results of the maximum von Mises stress in the $\mathrm{Cu}-\mathrm{Ni}$ via and the $\mathrm{Cu}$ via after cooling down to room temperature with increasing annealing temperature. The maximum stress increases with increasing annealing temperature. In particular, the maximum stress increases sharply at a temperature of $300^{\circ} \mathrm{C}$ possibly owing to the creep effect of via material. Higher annealing temperature generates larger creep deformation of $\mathrm{Cu}-\mathrm{Ni}$ and $\mathrm{Cu}$ TSV via, which is irreversible deformation and thus results in larger stress when temperature changes from annealing temperature to room temperature. At a higher annealing temperature, the stress increased slightly due to the softening effect of the $\mathrm{Cu}$ and $\mathrm{Cu}-\mathrm{Ni}$ via material. In general, the $\mathrm{Cu}-\mathrm{Ni}$ via exhibited lower stress level than the $\mathrm{Cu}$ via structure, however, the differences in stress level become small from $350^{\circ} \mathrm{C}$. At an annealing temperature of $300^{\circ} \mathrm{C}$, the maximum stress in the $\mathrm{Cu}-\mathrm{Ni}$ and $\mathrm{Cu}$ via is around 460 and $519 \mathrm{MPa}$, respectively. This thermal stress is high enough to cause plastic deformation of the $\mathrm{Cu}-\mathrm{Ni}$ and $\mathrm{Cu}$, and the via extrusion may remain even after cooling. Figure 14 reveals the maximum von Mises stress subjected to the silicon wafer with increasing annealing temperature. The maximum stress on the silicon wafer showed similar trend with the maximum stress on the via. The maximum stress increases with increasing annealing temperature due to an increase in the thermal expansion mismatch with the via. The maximum stress of $\mathrm{Cu}-\mathrm{Ni} \mathrm{TSV}$ and $\mathrm{Cu}$ TSV at an annealing temperature of $450^{\circ} \mathrm{C}$ is $1.08 \mathrm{GPa}$ and $1.12 \mathrm{GPa}$, respectively. The $\mathrm{Cu}-\mathrm{Ni}$ TSV showed a slightly lower stress value than the $\mathrm{Cu}$ TSV.

\section{Conclusion}

In this study, we investigated the characteristics of $\mathrm{Cu}-\mathrm{Ni}$ alloy via protrusions at various annealing temperatures. High speed $\mathrm{Cu}-\mathrm{Ni}$ alloy filling into vias was performed with the electroplating process using a periodic pulse reverse current waveform. The filled $\mathrm{Cu}-\mathrm{Ni}$ TSVs revealed a $100 \%$ filling ratio without defects and consisted of 92 mass $\% \mathrm{Cu}$ and 8 mass $\%$ Ni. Protrusions of the $\mathrm{Cu}-\mathrm{Ni}$ vias at various annealing temperatures were investigated with experimental and numerical analyses and compared with $\mathrm{Cu}$ vias. The size of the protrusions gradually increased with annealing temperature and started to increase substantially at $350^{\circ} \mathrm{C}$. The $\mathrm{Cu}-\mathrm{Ni} \mathrm{TSV}$ showed lower via protrusion relative to the $\mathrm{Cu}$ TSV. The simulated $\mathrm{Cu}-\mathrm{Ni}$ via protrusion heights were relatively well-matched with the experimentally measured data. The simulation results also showed that the Cu-Ni TSVs showed smaller protrusions than the $\mathrm{Cu}$ TSVs. As the annealing temperature increased, the $\mathrm{Cu}-\mathrm{Ni}$ via expanded vertically due to the CTE mismatch between the via and the surrounding materials. When the temperature increased to above $350^{\circ} \mathrm{C}$, protrusions became larger due to increased $\mathrm{Cu}$ creep deformation. The von Mises stress in the $\mathrm{Cu}-\mathrm{Ni}$ via increased with increasing annealing temperature, and increased substantially at a temperature of $300^{\circ} \mathrm{C}$ due to the creep effect of via material. Overall, the $\mathrm{Cu}-\mathrm{Ni}$ alloy TSV showed high speed filling and a lower via protrusion. This indicates that $\mathrm{Cu}-\mathrm{Ni}$ alloy vias represent a promising alternative to $\mathrm{Cu}$ vias for TSV technologies.

\section{Acknowledgments}

This work was supported by a grant from the Industrial Core Technology Development Program of "Development of inductor and power devices using thick $\mathrm{Cu}$ plate with $20 \mu \mathrm{m}$ thickness (10048344)" and "Development of thermo-compression joining technology with speed of $6 \mathrm{sec} / \mathrm{chip}$ and pitch size of $20 \mu \mathrm{m}$ (10051605)" funded by the Ministry of Trade, Industry \& Energy, Republic of Korea.

\section{REFERENCES}

1) T. Kobayashi, J. Kawasaki, K. Miura and H. Honma: Electrochim. Acta 47 (2001) 85-89.

2) M. Lefebvre, G. Allardyce, M. Seita, H. Tsuchida, M. Kusaka and S. Hayashi: Circuit World 29 (2003) 9-14.

3) N. Ranganathan, K. Prasad, N. Balasubramanian and K. L. Pey: J. Micromech. Microeng. 18 (2008) 075018.

4) E. J. Cheng and Y. L. Shen: Microelectron. Reliab. 52 (2012) 534-540.

5) I. De Wolf, K. Croes, O. V. Pedreira, R. Labie, A. Redolfi and M. V. Peer: Microelectron. Reliab. 51 (2011) 1856-1859.

6) L. W. Kong, A. C. Rudack, P. Krueger, E. Zschech, S. Arkalgud and A. C. Diebold: Microelectron. Eng. 92 (2012) 24-28.

7) F. X. Che, W. N. Putra, A. Heryanto and A. Trigg: IEEE Trans. Compon. Packag. Manuf. Technol. 3 (2013) 732-739.

8) T. Jiang, S. K. Ryu, Q. Zhao, J. Im, R. Huang and S. Paul Ho: Microelectron. Reliab. 53 (2013) 53-62.

9) A. Heryanto, W. N. Putra, A. D. Trigg, S. Gao, W. S. Kwon, F. X. Che, X. F. Ang, J. Wei, R. I. Made and C. L. Gan: J. Electron. Mater. 41 
(2012) 2533-2542.

10) C. Lee, S. Tsuru, Y. Kanda, S. Ikeda and M. Matsumura: J. Electrochem. Soc. 156 (2009) D543-D547.

11) K. Y. K. Tsui, S. K. Yau, V. C. K. Leung, P. Sun and D. X. Q. Shi: Proc. Int. Conf. on Electron. Pack. Tech. \& High Dens. Pack. (ICEPT-HDP), (2009) pp. 23-27.

12) J. S. Bae, G. H. Chang and J. H. Lee: J. Microelectron. Pack. Soc. 12 (2005) 129-134.

13) A. Pohjoranta and R. Tenno: J. Electrochem. Soc. 154 (2007) D502D509.

14) T. Dao, D. H. Triyoso, R. Mora, T. Kropewnicki, B. Griesbach, D Booker, M. Petras and V. Adams: Proc. Int. Symp. on VLSI Des. Aut. Test (VLSI-DAT), (2010) pp. 7-10.

15) Q. Chen, C. Huang and Z. Wang: Microelectron. Reliab. 52 (2012) 2670-2676.

16) A. Tsukada, R. Sato, S. Sekine, R. Kimura, K. Kishi, Y. Sato, Y. Iwata and H. Murata: Proc. 61st IEEE Electron. Comp. Tech. Conf. (ECTC),
(2011) pp. 1981-1986.

17) Y. Jee, J. Yu, K. Park and T. Oh: J. Electron. Mater. 38 (2009) 685-690.

18) R. He, H. Wang, J. Zhou, X. Guo, D. Yu and L. Wan: Proc. Int. Conf. on Electron. Pack. Tech. \& High Dens. Pack. (ICEPT-HDP), (2011) pp. 1-4.

19) Y. K. Ko, H. T. Fujii, Y. S. Sato, C. W. Lee and S. Yoo: Microelectron. Eng. 89 (2012) 62-64.

20) S. C. Hong, S. Kumar, D. H. Jung, W. J. Kim and J. P. Jung: Met. Mater. Int. 19 (2013) 123-128.

21) M. Gad-el-Hak: The MEMS Handbook, 2nd Ed., (CRC Press, 2002) p. 35 .

22) G. R. Blackwell: The Electronic Packaging Handbook, (CRC Press LLC, Florida, 2000) p. 521.

23) S. Park, H. C. Lee, B. Sammakia and K. Raghunathan: IEEE Trans. Compon. Packag. Technol. 30 (2007) 294-301.

24) G. Li, B. G. Thomas and J. F. Stubbins: Metall. Mater. Trans. A 31 (2000) 2491-2502 